\title{
Framing Business Sustainability Efforts Through Time
}

\author{
Göran Svensson and Nils M. Høgevold
}

\begin{abstract}
This study contributes to an understanding of how corporate efforts in connection with business sustainability appear to evolve along evolutionary paths over a timeline.

This research is based on a grounded methodology with information gathered from a series of different Norwegian companies, all of which are highly regarded in both the marketplace and broader society for their business sustainability efforts.

The objective of this study is to identify and describe the evolutionary paths involved in corporate efforts at business sustainability.

A qualitative approach was applied to a sample of companies, all well known for their significant and long-term efforts at business sustainability. Their efforts within the respective organisations, marketplace and society all go beyond the level of mere compliance with regulations. Six companies across different industries were selected.
\end{abstract}

The different evolutionary paths involved in corporate business sustainability efforts constitute a valuable contribution to the field. Business sustainability efforts are not static, but dynamic and based upon continuous flexibility to changes and adaptations over time.

We observe that all identified evolutionary paths of corporate efforts in relation to business sustainability are interconnected-some paths originate from the initial efforts, while other efforts and paths are a consequence of others.

The main contribution of this study is the set of evolutionary paths. Another complementary contribution exists in relation to Høgevold et al. (2014), although the current study extends and refines their framework of evolutionary paths.

We believe that the evolutionary paths displayed are relevant and useful to both scholars and practitioners.

A specific suggestion for further research is to further explore the existence of other evolutionary paths.

References available on request.

G. Svensson $(\bowtie) \bullet$ N.M. Høgevold

Kristiania University College, Oslo, Norway

e-mail: goran.svensson@kristiania.no; nils.hogevold@kristiania.no 